\title{
Exploring the Relationship between Ability Grouping and Science Vocabulary Learning
}

\author{
Patrick L. Brown ${ }^{1 *}$, James P. Concannon ${ }^{2}$ \\ ${ }^{1}$ Fort Zumwalt School District, Saint Charles, Missouri, United States of America, ${ }^{2}$ School of Education, William Woods University, Fulton, Missouri, \\ United States of America
}

*Corresponding Author: patbrown@fz.k12.mo.us

\section{ABSTRACT}

This study investigated $8^{\text {th }}$-grade science students (13-14 years old) in advanced and traditional ability classrooms perceptions of their vocabulary knowledge, learning, and content achievement. This research acknowledges the critical role that developing vocabulary knowledge from reading plays in gaining a deeper content understanding as well as promoting overall science literacy. Data sources included pre- and post-test of students' perceptions of vocabulary knowledge, students' perceptions of vocabulary and reading strategies surveys, and a content achievement test. Students' perceptions of vocabulary knowledge were compared before and after instruction to see whether students believed they gained knowledge and the ability to explain categories of technical science terms. Students' in both advanced and traditional classroom perceptions of vocabulary knowledge increased as a result of instruction. The participants had favorable views of the vocabulary and reading strategies implemented and believed that the literacy approaches were important for their developing scientific knowledge. Furthermore, students' content achievement was compared for the advanced and traditional groups. Although advanced class classes outperformed traditional courses on the content test, only one of the seven items was statistically significant. Both groups were compared to a national data set that served as a control and had statistically significant higher achievement than the national data set. Most of the inferential measures indicate that there is no statistically significant difference between the two groups. The combination of metacognitive awareness, close reading, and integrative vocabulary helped all students build complex schema surrounding science vocabulary, as evidenced by student's perceptions of knowledge and their content achievement. This study is one of the first to highlight the pivotal role students' perception of vocabulary knowledge and vocabulary and reading strategies plays in science content learning regardless of ability level.

KEY WORDS: vocabulary teaching; vocabulary learning; reading strategies; science literacy; classroom ability levels

\section{INTRODUCTION}

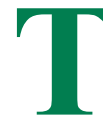
The professional work of scientists involves a range of research-related tasks that include: Conducting research, constructing evidence-based claims, disseminating research to peers and laypeople, reading and synthesizing research findings, methodologies, and other forms of technical reports for publication. Each of these actions is intended to build the body of knowledge and scholarship in a specialized area of study. Recent reforms in science education call for providing experiences for students that are cognitively appropriate and mirror the work of scientists. For example, science education reform highlights that the methods used to do science and content should be taught in unison and not separately (e.g., NRC, 2013; Osborne \& Dillon, 2008). The integration of content and practices allows students to develop the understanding that science provides a way of systematically and objectively better understanding the natural world. While the integration of content and practices is stressed now more than ever before, the scientific practices have focused mainly on skills and abilities to perform scientific inquiry. However, learning from reading is an integral part of a scientist's professional work that guides much of their practice and research-related endeavors.
In the USA, the Common Core State Standards (CCSS) highlight that instruction, regardless of academic discipline, should promote students gathering, comprehending, assessing, and synthesizing the information presented in technical texts required for college and career readiness (NGA \& CCSSO, 2010). The National Reading Panel (NICHD, 2000) identified vocabulary as imperative to reading comprehension and crucial to overall school success (Anderson \& Nagy, 1991). While developing students' abilities to learn from technical texts is an important goal, science informational texts can be challenging for learners because they provide a range in types of technical terminologies. Consider the formal science terminology of the excerpt shows from a middle school (students aged 13 and 14) science textbook:

There is a mathematical relationship between kinetic energy (KE), mass, and velocity.

$$
\mathrm{KE}=1 / 2 \times \text { mass } \times \text { velocity }^{2} .
$$

Do changes in velocity and mass have the same effect on KE? No - changing the velocity of an object will have a greater effect on its KE than changing its mass. This is because velocity is squared in the KE equation. For instance, doubling the mass 
of an object will double its KE. However, doubling its velocity will quadruple its KE (Frank et al., 2007. p. 444).

The passage contains formal science terminologies (e.g., "KE," "mass," and "velocity"); mathematical formulas (e.g., " $\mathrm{KE}=1 / 2 \mathrm{mv}^{2}$ '); and non-technical terms used to describe relationships (e.g., "doubling," and "quadruple"). The excerpt demonstrates the vocabulary demands placed on students in science and is representative of what they encounter when they read their middle school science textbook (Groves, 1995). In the above excerpt, the language is complex, abstract, and content-specific. The writing is lexically dense because it uses discipline-specific science words (e.g., KE) to describe complex processes (mass and velocity are related to each other in a mathematically proportional manner) (Carlsen, 2007; Meyers, 1991; Penney et al., 2003). To understand the excerpt, students must have a well-developed knowledge base and be able to read closely, decipher, and understand the relationship between different types of science concepts described using discipline-specific vocabulary.

The study reported here is consistent with research that acknowledges the key role reading plays in science learning (Brown \& Concannon, 2014, 2016). The purpose of this study is to compare middle school science students' perceptions of vocabulary knowledge, learning, and content achievement in advanced and traditional classes.

\section{Research Questions}

This study focused on research questions aimed at exploring students' perceptions and knowledge before and after the implementation of literacy strategies. The research questions were guided by constructivist theories of learning and include:

1. What are the differences in traditional and advanced class classes' perceptions of specific science vocabulary after learning science using literacy strategies?

2. What are the differences in advanced and traditional classes' perceptions of instructional strategies designed to learn formal science vocabulary?

3. What are the differences between advanced and traditional classes' content achievement?

\section{Theoretical Framework: Constructing Vocabulary Knowledge for Reading}

Vocabulary knowledge and understanding from reading are an integral part of science and science literacy. Constructing vocabulary knowledge is based on the idea that learners construct new ideas based on existing knowledge (Bruner, 1990). Vocabulary learning is an active cognitive process where students construct knowledge based on new and prior knowledge, personal and social experiences, and the content they are learning (Snow et al., 2005; Vygotsky, 1986). For students to learn vocabulary and learn from reading, they must construct knowledge based on their prior and new experiences with science (Nagy, 2005). Students' ability to make sense of the technical text is directly related to their past experiences with science and their capability to read and learn from the context of the narrative investigated. Learning from reading is an active interaction between what students know and information accessed from the texts. Readers must interactively process text-based information and their concurrent experiences as readers and with science (Kamil \& Hiebert, 2005).

The cognitive processes associated with reading are complex. Students must navigate language structures, linguistic rules, and science terminology as they consider ideas in the context of both their current scientific understanding and reading abilities. Readers construct understanding as they extract insights from reading that relates to their personal experiences. Consequently, a given student's science learning from reading is complex and dependent on the student's prior knowledge, new skills, the structure of the text, the student's reasoning ability, and the overall socio-cultural context of the learning environment (Gee, 2000). The theoretical framework guided the methodology and the constructivist literacy instructional strategies used in this study. In this regard, these bodies of research assert that readers learn best when they actively use their available resources to make sense of technical texts.

Conceptual Framework-constructivist Literacy Strategies The conceptual framework was undergirded by Grave's (2006) four-part, constructivist approach to vocabulary instruction that includes: (1) Teach a few terms at once, (2) teach vocabulary learning strategies and individual words simultaneously, (3) foster metacognition about knowledge development, and (4) provide rich and varied vocabulary learning experiences. Expert readers think about their learning from reading and choose strategies to help them develop deeper conceptual understanding termed metacognition (Nagy et al., 1985). Literacy practices are a means to construct more profound content knowledge and conceptual understanding. Lemke (1990) suggested that to read, write, and talk science students must go back and forth between new terms and experiences. Learning science through effective literacy practices require students to combine new terms, mental models, and representations, data, and evidence in ways that allow them to make sense of the world. Nagy (2005) acknowledged that learning the meaning of words is a complex interaction between students' prior knowledge and experience with content. Knowing the definition of isolated terms does not mean a student will understand what they read. To facilitate the construction of ideas, explicit close reading and vocabulary strategies help students develop content-specific vocabulary knowledge (Marzano, 2004; Marzano et al., 2001; Yager, 1983). In this way, effective vocabulary instruction provides students with multiple exposures and varied tasks to new words beyond simply defining terms and allows them to actively process the words meaning in various contexts over time (Graves et al., 2013).

\section{LITERATURE REVIEW}

The ultimate goal in science education is that all students achieve science literacy. Science literacy means students leave 
science classrooms with broad knowledge and appreciation for science, so they can be critical of science, communicate science ideas, and relate new knowledge to their daily lives (Bybee, 1997). Yore et al. (2003) argued that a fundamental component of being scientifically literate means that students develop the ability to "speak, read, and write in and about science" (p. 690). Millar and Osborne (1998) suggested one's ability to read, understand, and respond critically to newspaper articles and scientific reports as central to obtaining higher levels of science literacy. Thus, language and literacy are central to achieving science literacy.

Scholarship in literacy education demonstrates vocabulary teaching, and reading strategies help students learn. For instance, having students explain confusing terms while reading aids their development of conceptual understanding (Reutzel \& Cooter, 1992). Vocabulary strategies that explicitly help students describe new ideas (e.g., Anderson \& Nagy, 1991), ask students to use new terms and concepts in many contexts (e.g., Beck et al., 2002), and require students to have multiple exposures to new ideas (e.g., Stahl, 2005), expand a learner's knowledge. Vocabulary strategies that go beyond memorization and have students think and ask questions about words meaning help promote long-lasting understanding (Brabham \& Villaume, 2001). Furthermore, studies show that close reading complex texts lead to significant gains in both struggling and advanced readers' reading proficiency (PARCC, 2011). Some studies in science education corroborate the research in literacy education and show that using specific literacy strategies in science improve comprehension and engagement (Gregg \& Sekeres, 2006; Guthrie et al., 1996; Harmon et al., 2009; Yates et al., 2011). Scholarship by Gruber (2011) has shown that knowing and understanding the meaning of as little as 20 prefixes and fourteen roots can help students understand the meaning of thousands of new words.

While language and vocabulary are emphasized now more than ever before, the specific role of reading in science education for the past 30 years has not been clearly articulated (Yore et al., 2003). English language arts reforms promote language literacy by stressing that all students develop conceptual knowledge of discipline-specific vocabulary as presented by technical texts (NGA \& CCSSO, 2010). Furthermore, English language arts initiatives highlight that teaching students how to think and self-monitor understanding while reading challenging technical texts prepares them to be more college and career ready (PARCC, 2011). To this date, science education standards say little about precise applications of reading and literacy practices that help all students regardless of ability in science classrooms. The purpose of this study is to explore the effectiveness of literacy practices on students' perceptions of knowledge and content achievement who have different ability levels.

\section{METHODOLOGY}

Ninety-two students age 13 and 14 participated in the study that represents two separate data sets: Advanced class $(n=41)$ and traditional class classes $(n=51)$ (parental consent was obtained for participants). Advanced courses were composed of students who were recommended by teachers based on prior science and mathematical knowledge, course grades, homework completion, and work ethic. All other students enrolled in the traditional science course. All students were enrolled in the first author's classes. Data collection occurred during the $4^{\text {th }}$ month of the school year when students began their unit on types of energy and energy transformation. Types of energy and energy transformations are in the district curriculum based on K-12 Science Education Frameworks (NRC, 2013). Identifiers were removed before analysis of all data to maintain student confidentially and protect identity. Furthermore, all results about students' perceptions and content tests were analyzed for research purposes and reported in aggregate form with all identifiers removed after the completion of the course and final grades submitted.

\section{Constructivist Instructional Approaches}

Multiple constructivist learning approaches were used to help students develop vocabulary knowledge. The constructivist strategies were a part of regular class activities and asked students individually and as a group to think about their understanding of vocabulary at all stages of content knowledge development. The learning environment focused on clearly and frequently articulated learning goals for students. Students were told explicitly at the beginning of lessons, the target vocabulary ideas and when they are addressed during the experience. During the lesson, students used text excerpts and class discussions to think about vocabulary learning, make sense of new terminologies, and connect meanings to everyday life.

The teacher modeled metacognitive strategies during class by reading out loud and talking through a logical sequence of thinking helpful for learning new ideas. Furthermore, the teacher talked through how they used context clues to decipher the meanings of terms and reflect on how their knowledge was developing over time (Nagy et al., 1985). The teacher promoted mindfulness and reflection by teaching students to consider prior content knowledge, and strategies have been used in the past when reading technical texts and learning vocabulary. For example, the instructor asked students to think about their confidence in their understanding of new ideas and the specific factors that help facilitate knowledge development. The teacher frequently used a script where they said, "at first we all thought (insert idea here), and know we think (insert idea here). Why did our ideas change?" Inherent in the answer to questions such as these are comments about the purposeful use of literacy approaches used to help students think about the relationship of new knowledge and effective instructional strategies. The premise behind careful reflection was that past successes and failures would provide plausible and fruitful strategies to aid comprehension (Hattie, 2009). In this way, students' background knowledge and recent achievements were used to build confidence in their abilities to learn from technical texts. While reading, students were asked to self-monitor their 
understanding by reflecting on what they believe they know and do not understand. In addition to the constructivist nature of the class, students used literacy-specific strategies based on research in literacy education (Marzano, 2004; Marzano et al., 2001; Nagy et al., 1985; Yager, 1983). The instructional practices focused on two primary strategies grounded in the reading research and Grave et al.'s (2013) 4-part literacy approach: Close reading and integrated vocabulary.

\section{Close reading}

Students also used close reading techniques to delve into the intricacies and elaborate on the texts they were reading. Close reading activities asked students to ask questions about the text they were reading and suggest content questions that could be used to assess their understanding of the reading (Brown, 2016). To engage with readings, students used a close-reading strategy called the five S strategy (Nyberg \& Shelnut, 2004). Close reading is an activity where students interact with the text individually, with peers, and with the teacher to jot down notes, highlight, and annotate to develop deeper understanding using the following analytical lenses: structure, speaker, situation, shifts, and summary statement. The specific analytical "S" of each lens became the reading activity versus the product of the reading. Thus, the five $\mathrm{S}$ strategy provided students with a method for engaging in the intricacies of text and exposed them to multiple perspectives to develop more in-depth content, and literacy understanding. Students also used close reading strategies when answering test questions (Brown et al., 2018). For example, during tests, students were taught to construct diagrams to represent and simplify the information presented in complex technical texts.

\section{Integrative vocabulary strategies}

For new formal science terminology, students used integrated vocabulary strategies. Integrated vocabulary strategies asked students to define terms, make visual representation to symbolize terms, provide examples of new vocabulary that relate to everyday life, created test questions about words, and offer descriptions of terms so that novices could learn new ideas (Marzano, 2004; Marzano et al., 2001; Yager, 1983).

\section{Content}

Content associated with energy transformations and conservation of energy was purposefully chosen due to the scientific vocabulary related to abstract concepts that are inaccessible from hands-on alone. While national standards emphasize that students distinguish between energy types and understand how energy is conserved during an energy transformation, they must attach the meaning of scientific terminology to an idea. For example, the term KE is used to describe the motion energy of an object. An object at rest that falls undergoes an energy transformation from potential energy to KE. Students cannot physically see the energy transfer that occurs. Instead, they attach meaning to these terms from their experiences with them in science. Some of the challenges are due to students learning new words without using the practices of science to develop a conceptual understanding.

\section{Data Sources}

Students participated in pre- and post-test perceptions of vocabulary knowledge and learning that prompted students thinking about what they already know and what they will learn and could contribute to students' developing understanding (Brown \& Concannon, 2014, 2016). A three-point response scales were employed to assess students' perceptions of vocabulary knowledge (both pre- and post-test) (I know and can explain terminology, I know [familiar but cannot explain] terminology, or I do not know the terminology) (Brown \& Concannon, 2016). Students' pre-test and post-test vocabulary scores were composed of three separate subscales labeled: Formal, Prior Formal, and Relationship (Brown \& Concannon, 2016) (Table 1). The actual pre- and post-test consisted of each of the terms shown in Table 1 and the three-point scale mentioned above used by students to self-evaluate their understanding.

A three-point scale was used to assess students' perceptions of literacy strategies (agree, neutral, or disagree). The perceptions of literacy strategies post-test included questions about vocabulary and close reading strategies used during the time of the study (Tables 2-4). Furthermore, some questions asked students whether they thought they could use a close reading or vocabulary strategy on their own to learn the material or teach a peer how to use the specific approach to learn. The survey questions used in Tables 2-4 included the option for students to respond whether they agree, were neutral, or disagreed with the statement.

Students completed a content knowledge test as a regular part of the course. When students took the content assessment, they could skip or not answer questions. The items on the content test explicitly addressed disciplinary core ideas identified by the K-12 Science Education Frameworks and evaluated by the American Association for the Advancement of Science (AAAS) project 2061 Assessment website (AAAS, n.d.). The content items dealt with students developing an understanding of energy and transformations (NRC, 2013). The questions were piloted with a national data set $(n=1000)$. The national data set served as a control group for comparison.

\begin{tabular}{ll}
\hline Table 1: Subscales of science vocabulary \\
\hline Subscale & Terminology \\
\hline Formal & $\begin{array}{l}\text { Kinetic energy, potential energy, energy } \\
\text { transformations, gravitational potential energy, elastic } \\
\text { potential energy, chemical energy, electrical energy, } \\
\text { thermal energy, law of conservation of energy, nuclear } \\
\text { energy, electromagnetic energy, mechanical energy, } \\
\text { nuclear reaction, energy, nuclear fission, power } \\
\text { Chemical, velocity, nucleus, friction, matter, newton, } \\
\text { infrared radiation, particles, microwaves, ultraviolet } \\
\text { radiation, atoms, X-rays, radio waves, magnetism, cells, } \\
\text { mass, compounds, meters, molecules, motion, speed } \\
\text { Compress, efficient, unwinds, transfer, identical, } \\
\text { quadruple, reversed, associated }\end{array}$ \\
\hline
\end{tabular}




\section{Data Analysis}

The availability of two separate data sets made it possible to conduct a secondary reanalysis (Yore et al., 2009). To perform a reanalysis, all of the data, collection instruments, and response scales were standardized. Additional data sets collected were combined into one extensive data set to investigate different research questions (Hinds et al., 1997; Szabo \& Strang, 1997). This study builds on prior research that only looked at advanced student's perceptions of vocabulary knowledge and learning (Brown \& Concannon, 2016). This study added a comparison group to determine whether differences might occur for advanced versus traditional students. In this way, other scholars used a secondary approach and re-used their data in light of a new perspective (Bull \& Kane, 1996). The analysis of the perceptions of vocabulary knowledge, literacy strategies, and content achievement are described below.

\section{Perceptions of vocabulary knowledge}

On the perceptions of vocabulary knowledge assessment, inferential, and descriptive statistics were used to determine whether statistically significant differences occurred for pre- and post-test between two groups: Advanced and traditional classes. Differences between advanced and traditional courses for the three subscales (e.g., formal, old formal, and relationship) were tested for statistical significance using an independent samples t-test. For statistically significant tests, Cohen's d effect size was calculated to determine the magnitude of the effect (Cohen, 1988).

\section{Perceptions of literacy strategies}

To analyze the perceptions of literacy strategies survey items, the literacy strategy (Tables 2-4) was coded according to their ability to promote metacognition. For example, if the statement was related to students' perceptions of their abilities to reflect on what they will know or be able to do were coded

Table 2: Comparisons of advanced and traditional classes' perceptions of vocabulary strategies used to learn science

\begin{tabular}{|c|c|c|c|}
\hline Item & Advanced classes $n=41(\%)$ & Traditional classes $n=51(\%)$ & Chi-squared \\
\hline $\begin{array}{l}\text { Taking notes was important for helping me } \\
\text { learn new science vocabulary }\end{array}$ & 81 & 61 & $\chi^{2}(1)=4.32, \rho<0.05^{*}$ \\
\hline $\begin{array}{l}\text { Watching videos helped me learn new } \\
\text { vocabulary }\end{array}$ & 75 & 67 & $\chi^{2}(1)=0.7, \rho>0.05$ \\
\hline $\begin{array}{l}\text { Learning new science vocabulary is important } \\
\text { for my future success }\end{array}$ & 70 & 65 & $\chi^{2}(1)=0.26, \rho>0.05$ \\
\hline $\begin{array}{l}\text { Understanding science vocabulary will help } \\
\text { me understand the world around me }\end{array}$ & 65 & 61 & $\chi^{2}(1)=0.16, \rho>0.05$ \\
\hline $\begin{array}{l}\text { Learning science vocabulary is a good use of } \\
\text { class time }\end{array}$ & 84 & 81 & $\chi^{2}(1)=0.14, \rho>0.05$ \\
\hline $\begin{array}{l}\text { Drawing pictures to illustrate new terms helped } \\
\text { me learn science vocabulary }\end{array}$ & 63 & 68 & $\chi^{2}(1)=0.25, \rho>0.05$ \\
\hline I enjoy learning new science vocabulary & 53 & 60 & $\chi^{2}(1)=0.45, \rho>0.05$ \\
\hline $\begin{array}{l}\text { We did a lot of interesting vocabulary activities } \\
\text { in science class }\end{array}$ & 51 & 63 & $\chi^{2}(1)=1.34, \rho>0.05$ \\
\hline $\begin{array}{l}\text { The science vocabulary pre-test was helpful for } \\
\text { introducing new terms before I learned them }\end{array}$ & 56 & 68 & $\chi^{2}(1)=1.4, \rho>0.05$ \\
\hline $\begin{array}{l}\text { I would like to learn more strategies to learn } \\
\text { vocabulary in science }\end{array}$ & 26 & 54 & $\chi^{2}(1)=7.34, \rho<0.05^{*}$ \\
\hline I look forward to vocabulary activities in & 28 & 60 & $\chi^{2}(1)=9.38, \rho<0.05^{*}$ \\
\hline
\end{tabular}

science class

$* \rho<.05$. We are $95 \%$ confident that there is a difference

Table 3: Comparisons of advanced and traditional classes' perceptions of close reading strategies used to learn science

\begin{tabular}{|c|c|c|c|}
\hline Item & Advanced classes $n=41(\%)$ & Traditional classes $n=51(\%)$ & Chi-squared \\
\hline $\begin{array}{l}\text { If I try hard, I can understand most science ideas based } \\
\text { from reading }\end{array}$ & 86 & 63 & $\chi^{2}(1)=6.14, \rho<0.05^{*}$ \\
\hline $\begin{array}{l}\text { Writing and solving my own math problems after close } \\
\text { reading text helped me learn vocabulary and concepts }\end{array}$ & 60 & 39 & $\chi^{2}(1)=4.01, \rho<0.05^{*}$ \\
\hline $\begin{array}{l}\text { My science teacher encouraged me to understand } \\
\text { concepts during close readings }\end{array}$ & 88 & 91 & $\chi^{2}(1)=0.22, \rho>0.05$ \\
\hline $\begin{array}{l}\text { During a close read, it helps me when the teacher reads } \\
\text { out loud }\end{array}$ & 44 & 53 & $\chi^{2}(1)=0.74, \rho>0.05$ \\
\hline $\begin{array}{l}\text { The close reading strategy helped me learn about } \\
\text { vocabulary }\end{array}$ & 58 & 72 & $\chi^{2}(1)=1.98, \rho>0.05$ \\
\hline
\end{tabular}

$* \rho<0.5$. We are $95 \%$ confident that there is a difference 
as metacognitive. Chi-squared tests were used to investigate students' perceptions of vocabulary strategies at a finer level.

\section{Content achievement}

To compare advanced and traditional classes' content achievement, Chi-squared tests were performed to investigate patterns that may occur for advanced versus traditional classes' content achievement for the items assessed. Chi-squared tests were also used to compare advanced and traditional courses with a national data set. Appendix A for content assessment items.

\section{RESULTS}

The results are presented to the three research questions. In the first section, findings are shared for differences in advanced and traditional classes' perceptions of knowledge of vocabulary after learning using literacy strategies. The second section presents differences in advanced and traditional course perceptions of literacy strategies used to help them learn vocabulary. The third section compares advanced and traditional classes' content achievement. The final section examines the effect of grouping (i.e., advanced vs. traditional) on students' perceptions of vocabulary knowledge, their perceptions of learning, and content achievement.

\section{Comparison of Student Perceptions of Vocabulary Knowledge}

Table 5 and Figure 1 compare advanced and traditional classes' perceptions of knowledge on the pre- and post-test for formal, prior formal, and relationship terminology. As shown in Table 5, there were statistical differences between advanced and traditional classes' perceptions of knowledge for

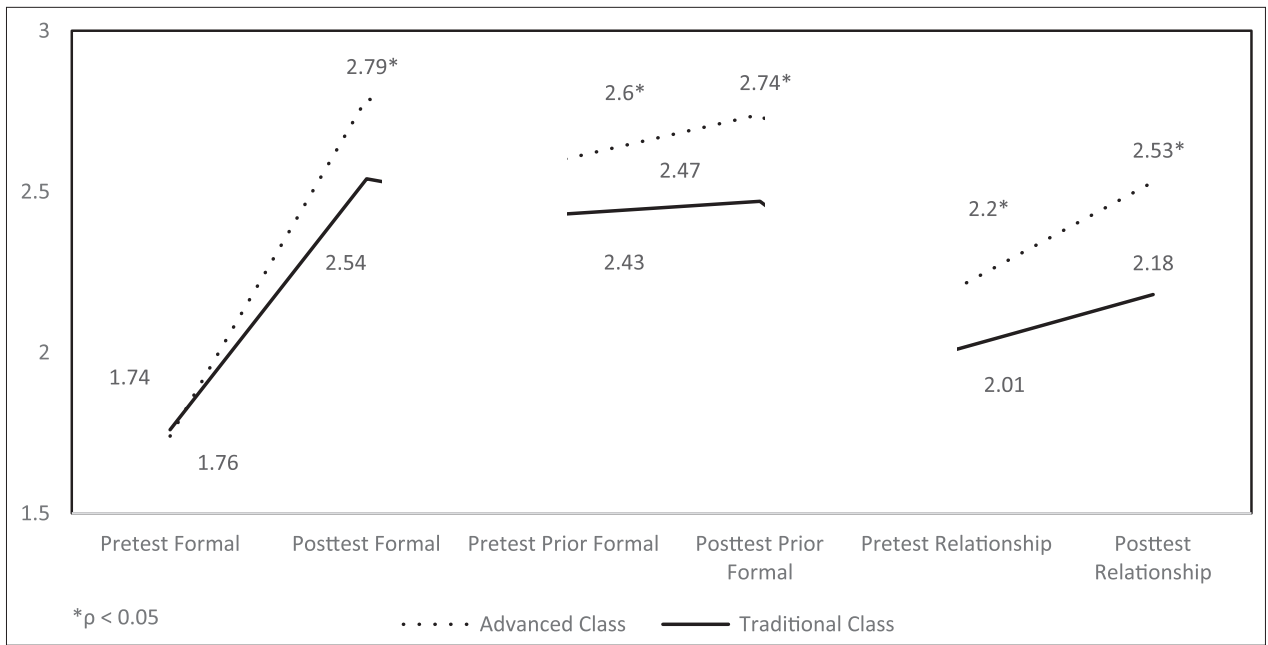

Figure 1: Comparisons within and between advanced class and traditional class. Students' perceptions of knowledge of formal, prior formal, and relationship terminologies

Table 4: Comparisons of advanced and traditional classes' perceptions of metacognitive strategies used to learn science

\begin{tabular}{|c|c|c|c|}
\hline Item & Advanced classes $n=41(\%)$ & Traditional classes $n=51(\%)$ & Chi-squared \\
\hline $\begin{array}{l}\text { I am confident that I can use vocabulary strategies from } \\
\text { class on my own to understand new science terms }\end{array}$ & 74 & 75 & $\chi^{2} 2(1)=0.01, \rho>0.05$ \\
\hline $\begin{array}{l}\text { I can help someone learn science from reading a text } \\
\text { that was having difficulty }\end{array}$ & 77 & 47 & $\chi^{2} 2(1)=8.55, \rho<0.05^{*}$ \\
\hline $\begin{array}{l}\text { I could teach another student how to close read a } \\
\text { section of text }\end{array}$ & 77 & 68 & $\chi^{2}(1)=0.91, \rho>0.05$ \\
\hline $\begin{array}{l}\text { During a close reading, I learn more from reading on } \\
\text { my own }\end{array}$ & 57 & 49 & $\chi^{2}(1)=0.58, \rho>0.05$ \\
\hline $\begin{array}{l}\text { I will use the close reading strategies when answering } \\
\text { difficult test questions }\end{array}$ & 70 & 65 & $\chi^{2}(1)=0.26, \rho>0.05$ \\
\hline $\begin{array}{l}\text { I can use the close reading strategy on my own to learn } \\
\text { some material }\end{array}$ & 37 & 37 & $\chi^{2}(1)=0, \rho>0.05$ \\
\hline $\begin{array}{l}\text { The close reading strategy will be useful in solving } \\
\text { everyday life problems that involve reading }\end{array}$ & 47 & 49 & $\chi^{2}(1)=0.04, \rho>0.05$ \\
\hline $\begin{array}{l}\text { I will use the close reading strategies when answering } \\
\text { challenging items on the MAP test }\end{array}$ & 81 & 86 & $\chi^{2}(1)=0.42, \rho>0.05$ \\
\hline $\begin{array}{l}\text { If I had to read about new and difficult science ideas, I } \\
\text { could use strategies from class to learn new vocabulary }\end{array}$ & 72 & 79 & $\chi^{2}(1)=0.61, \rho>0.05$ \\
\hline
\end{tabular}

$* \rho<0.5$. We are $95 \%$ confident that there is a difference 
Table 5: Comparisons of advanced and traditional classes' pre- and post-test perceptions of knowledge and ability to explain categories of science terminologies

\begin{tabular}{llccc}
\hline Terminology & Time & Advanced versus traditional mean & Diff. & Independent samples t-test, Cohen's d effect size \\
\hline Formal & Pre (T1) & 1.74 versus 1.76 & 0.02 & $\mathrm{t}(90)=-0.51, \rho>0.05$ \\
& Post (T2) & 2.79 versus 2.54 & -0.25 & $\mathrm{t}(90)=8.6, \rho<0.05, \mathrm{~d}=0.31^{*}$ \\
Prior formal & Pre (T1) & 2.60 versus 2.43 & -0.17 & $\mathrm{t}(90)=6.3, \rho<0.05, \mathrm{~d}=0.18^{*}$ \\
& Post (T2) & 2.74 versus 2.47 & -0.27 & $\mathrm{t}(90)=11.06, \rho<0.05, \mathrm{~d}=0.32^{*}$ \\
Relationship & Pre (T1) & 2.20 versus 2.01 & -0.19 & $\mathrm{t}(90)=3.17, \rho<0.05, \mathrm{~d}=0.17 *$ \\
& Post (T2) & 2.53 versus 2.18 & -0.35 & $\mathrm{t}(90)=6.47, \rho<0.05, \mathrm{~d}=0.38^{*}$
\end{tabular}

$* \rho<0.05$

all three subscales of knowledge (e.g., formal, prior formal, and relationship) at both time points (e.g., pre- and post-test). Five of the six measures were statistically significant and advanced classes had more positive perceptions of knowledge. There was no significant difference between advanced and traditional classes' perceptions of knowledge for formal terminology on the pretest (1.74 vs. 1.76, respectively). The effect size was most significant for the post-test on relationship terminologies where advanced classes had more positive perceptions of knowledge $(\mathrm{d}=0.38)$.

\section{Comparison of Perceptions of Literacy Strategies}

Tables 2 to 4 show a comparison of advanced and traditional classes' perceptions of literacy strategies used to learn science. There was no significant difference for eight of the eleven items assess that dealt with student's perceptions of vocabulary (Table 2). Only two of the five items assessed concerning student's perceptions of close reading strategies were statistically significant (Table 3). Finally, there were little differences in student's perceptions of metacognitive strategies used to help students learn science from literacy strategies (both vocabulary and close reading) (Table 4).

\section{Content Achievement}

Table 6 shows a comparison of content achievement for advanced versus traditional classes for individual items. Advanced courses had more favorable scores on item 6 ( $88 \%$ vs. $62 \%$ correct responses, respectively) and item 5 (95\% vs. $84 \%$ correct responses, respectively). There was no statistically significant difference between the advanced and traditional students' content achievement on items $1-5$ and 7 (Table 6).

As shown in Tables 7 and 8, students in both the advanced and traditional classes, outperformed students from the national data set on all items assessed.

\section{DISCUSSION}

Developing science literacy is an essential goal for all students, and disparities in student preparation and achievement by ability grouping could be indicators of educational inequities. This study aimed to investigate whether metacognitive

\begin{tabular}{|c|c|c|c|}
\hline Item & $\begin{array}{c}\text { Advanced classes } \\
n=41(\%)\end{array}$ & $\begin{array}{c}\text { Traditional } \\
\text { classes } n=51(\%)\end{array}$ & Chi-squared \\
\hline 1 & 95 & 90 & $\chi^{2}(1)=0.79, \rho>0.05$ \\
\hline 2 & 93 & 88 & $\chi^{2}(1)=0.64, \rho>0.05$ \\
\hline 3 & 97 & 98 & $\chi^{2}(1)=0.1, \rho>0.05$ \\
\hline 4 & 88 & 80 & $\chi^{2}(1)=1.06, \rho>0.05$ \\
\hline 5 & 95 & 84 & $\chi^{2}(1)=2.79, \rho>0.05$ \\
\hline 6 & 88 & 62 & $\chi^{2}(1)=7.9, \rho<0.05^{*}$ \\
\hline 7 & 63 & 56 & $\chi^{2}(1)=0.46, \rho>0.05$ \\
\hline
\end{tabular}

$\begin{aligned} & \text { Table 7: Comparisons of advanced and AAAS (national } \\
& \text { data set), content achievement }\end{aligned}$
\begin{tabular}{lccc} 
Item & $\begin{array}{c}\text { Advanced class } \\
\mathbf{n = 4 1}(\%)\end{array}$ & $\begin{array}{c}\text { AAAS } \\
\mathbf{n = 1 0 0 0}(\%)\end{array}$ & Chi-squared \\
\hline 1 & 95 & 58 & $\chi^{2}(1)=22.37, \rho<0.05^{*}$ \\
2 & 93 & 42 & $\chi^{2}(1)=41.57, \rho<0.05^{*}$ \\
3 & 97 & 61 & $\chi^{2}(1)=21.76, \rho<0.05^{*}$ \\
4 & 88 & 48 & $\chi^{2}(1)=25.21, \rho<0.05^{*}$ \\
5 & 95 & 53 & $\chi^{2}(1)=28.03, \rho<0.05^{*}$ \\
6 & 88 & 56 & $\chi^{2}(1)=16.48, \rho<0.05^{*}$ \\
7 & 63 & 53 & $\chi^{2}(1)=1.58, \rho<0.05^{*}$ \\
\hline
\end{tabular}

$* \rho<0.05$, AAAS: American Association for the Advancement of Science

strategies and literacy practices used with advanced and traditional classes lead to differences in their perceptions of vocabulary knowledge, perceptions of vocabulary learning, and content achievement. The comparison analysis showed there was a statistically significant difference between advanced and traditional classes' perceptions of vocabulary knowledge. Both groups of students believed that the literacy strategies were beneficial for their development of vocabulary knowledge; however, there were contrasts in the groups' enjoyment of vocabulary strategies and desires to learn additional approaches. The most significant difference in perceptions of vocabulary strategies used to learn science was related to whether students looked forward to vocabulary in science ( $60 \%$ traditional vs. $28 \%$ advanced class) and would 


\begin{tabular}{|c|c|c|c|}
\hline Item & $\begin{array}{c}\text { Traditional } \\
\text { class } n=51(\%)\end{array}$ & $\begin{array}{c}\text { AAAS } \\
n=1000(\%)\end{array}$ & Chi-squared \\
\hline 1 & 90 & 58 & $\chi^{2}(1)=16.96, \rho<0.05^{*}$ \\
\hline 2 & 88 & 42 & $\chi^{2}(1)=34.27, \rho<0.05^{*}$ \\
\hline 3 & 98 & 61 & $\chi^{2}(1)=23.31, \rho<0.05^{*}$ \\
\hline 4 & 80 & 48 & $\chi^{2}(1)=16.39, \rho<0.05^{*}$ \\
\hline 5 & 84 & 53 & $\chi^{2}(1)=15.49, \rho<0.05^{*}$ \\
\hline 6 & 62 & 56 & $\chi^{2}(1)=0.68, \rho<0.05^{*}$ \\
\hline 7 & 56 & 53 & $\chi^{2}(1)=0.24, \rho<0.05^{*}$ \\
\hline
\end{tabular}

like to learn more vocabulary strategies (54\% traditional vs. $26 \%$ advanced class). If we consider the findings in tandem, the traditional classes had less confidence in their knowledge of terms and believed they needed more opportunities to learn words. Although advanced classes consistently had higher content achievement overall; an item analysis showed that only one item (item 6) yielded a statistically significant difference in performance. The significance of these findings related to predictability suggests that the two different classes were taught using very similar strategies and led to remarkably congruent learning experiences for students. The main difference seems to be related to students' perceptions of their knowledge, and the strategies they believed would be beneficial for learning. All students had equitable science learning experiences.

This study corroborates research in literacy education (Anderson \& Nagy, 1991; Beck et al., 2002; Stahl, 2005; Reutzel $\&$ Cooter, 1992) and in science education (Gregg \& Sekeres, 2006; Guthrie et al., 2011; Yates et al., 2011) that show literacy strategies improve student engagement and comprehension. The findings of this study expand on the above research and deepen our understanding of how students' best learn science vocabulary when using literacy strategies. The lack of statistically significant differences between advanced and traditional groups on the content tests shows that amalgamation of metacognitive awareness and effective literacy strategies (both vocabulary strategies and close reading) lead to a robust experience for all students that enhanced science learning. Data support this assertion and show that students had similar content achievement in traditional and advanced classes (there was no statistically significant difference for six of the seven items) and outperformed the national data set (all seven items were statistically significant).

The focus on using effective literacy strategies could help students develop more confidence in their ability to read and learn from informational texts. For example, students had repeated experiences where they could reflect on their successes in learning from reading to build confidence in their abilities. Furthermore, by providing students structured expectations from close readings (e.g., having students annotate and summarize their understanding, connect text to their daily lives, and pose questions) allowed them multiple opportunities to develop understanding in a variety of context. Using integrated vocabulary strategies provided the chance to delve even deeper into knowledge by enabling students to make explicit connections between definitions, multiple examples, and creating visual representations of content.

The classroom culture that valued metacognitive awareness and the instructional strategies close reading and integrative vocabulary, helped all students build complex schema surrounding science vocabulary. Students interactively processed information by going back and forth between text-based explanations and their experiences as readers, with science, and in everyday life. Having multiple opportunities to transfer knowledge helped students clarify their understanding from reading technical texts and promoted high levels of content achievement. Thus, literacy strategies helped all students achieve higher levels of science literacy.

\section{CONCLUSIONS}

Despite growing interest in the use of reading and vocabulary strategies in science education, literacy practices remain an under-developed and ill-defined approach in science education. This research is one of the first studies to provide a more nuanced view of vocabulary learning in science using critical ideas about learning and cognition (Bransford et al., 2000). The science education community would benefit from more studies to further verify the robustness of the combination of metacognitive awareness and literacy practices on student learning and achievement. Next, science teachers must understand that integrating metacognitive awareness and literacy practices are an effective means of achieving higher levels of science literacy. Finally, teacher preparation and professional development programs must incorporate metacognitive awareness practices and literacy approaches into their education programs. The benefit of promoting metacognitive awareness and literacy practices in science education is that they provide students with engaging strategies to learn content and empower them with greater science literacy.

\section{REFERENCES}

American Association for the Advancement of Science (AAAS) Project 2061. (n.d.). Pilot and Field Test Data Collected between 2006 and 2010. Unpublished Raw Data. Available from: http://www.assessment. aaas.org. [Last accessed on 2012 Sep 16].

Anderson, R., \& Nagy, W. (1991). Word meanings. In: Barr, R., Kamil, M., Mosenthal, P., \& Pearson, P.D. (Eds.), Handbook of Reading Research. Vol. 2. New York: Longman. p690-724.

Beck, I.L., \& McKeown, M.G. (1986). Instructional research in reading: A Retrospective. In: Orasanu, J. (Ed.), Reading Comprehension: From Research to Practice. Hillsdale, NJ: Lawrence Erlbaum Associates. p113-134.

Beck, I.L., \& McKeown, M.G. (1991). Social studies texts are hard to understand: Mediating some of the difficulties. Language Arts, 68, 482-490.

Beck, I.L., McKeown, M.G., \& Kucan, L. (2002). Bringing words to life. New York, NY: Guilford.

Brabham, E.G., \& Villaume, S.K. (2001). Building walls of words. The Reading Teacher, 54(7), 700-702.

Bransford, J.D., Brown, A.L., \& Cocking, R.R. (2000). How People Learn: 
Brain, Mind, Experience, and School. Washington, DC: National Academy Press.

Brown, P. (2016). Accelerating science learning with reading. Science Scope, 40(3), 22-27.

Brown, P., Holloway, C., Hopkins, K., Scoles, A., Bumgarner, B., \& Hecktor, J. (2018). Using a shared literacy perspective to tackle informational texts. Engaging Culture and Voices, 9, 6-15.

Brown, P.L., \& Concannon, J. (2016). Students' perceptions of vocabulary knowledge and learning in a middle school science classroom. International Journal of Science Education, 38(3-4), 391-408.

Brown, P.L., \& Concannon, J.P. (2014). Investigating student perceptions of vocabulary and learning in middle school science. Advances in Social Sciences Research Journal, 1(3), 196-206.

Bruner, J. (1990). Acts of Meaning. Cambridge, MA: Harvard University Press.

Bull, M.J., \& Kane, R.L. (1996). Gaps in discharge planning. Journal of Applied Gerontology, 15(4), 486-500.

Bybee, R. (1997). Achieving Scientific Literacy. Portsmouth, NH: Heinemann.

Carlsen, W.S. (2007). Language and science learning. In: Abell, S.K., \& Lederman, N.G. (Eds.), Handbook of Research on Science Education. Mahwah, NJ: Lawrence Erlbaum Associates. p57-74.

Cohen, J. (1988). Statistical Power Analysis for the Behavioral Sciences. $2^{\text {nd }}$ ed. Hillsdale, NJ: Lawrence Earlbaum Associates.

Frank, D.V., Jones, G.T., Little, J.G., Miaoulis, B., Miller, S., Pasachoff, J.M., \& Wainwright, C. (2007). Science Explorer: Physical Science. Boston, MA: Pearson Prentice Hall.

Gee, J.P. (2000). The new literacy studies: From "socially situated" to the work of the social. In: Barton, D., Hamilton, M., \& Ivanic, R. (Eds.), Situated Literacies: Reading and Writing in Context. London: Routledge. p180-196.

Graves, M.F. (2006). The Vocabulary Book: Learning and Instruction. New York: Teachers College Press.

Graves, M.F. Baumann, J., Blachowich, C., Manyok, P., Bates, A., Cieply, C., Davis, J., \& Von Gunten, H. (2013). Words, words, everywhere, but which ones do we teach? The Reading Teacher, 67(5), 333-346.

Gregg, M., \& Sekeres, D. (2006). Supporting reading of expository text in the geography classroom. The Reading Teacher, 60(2), 102-110.

Groves, F.H. (1995). Science vocabulary load of selected secondary science textbooks. School Science and Mathematics, 95(5), 231-235.

Gruber, G. (2011). Gruber's SAT 24000: Strategies for Top-scoring Students. $2^{\text {nd }}$ ed. Naperville, IL: Sourcebooks.

Guthrie, J.T., Van Meter, P., McCann, A.D., Wigfield, A., Bennett, L., Punndstone, C.C., Rice, M.E., Faibisch, F.M., Hunt, B., \& Mitchell, A.M. (1996). Growth of literacy engagement: Changes in motivations and strategies during concept-oriented reading instruction. Reading Research Quarterly, 31, 306-332.

Harmon, J.M., Wood, K.D., \& Kiser, K. (2009). Promoting vocabulary learning with the interactive word wall. Middle School Journal, 40(3), 58-63.

Hattie, J.A.C. (2009). Visible Learning: A Synthesis of over 800 Metaanalyses Relating to Achievement. London, UK: Routledge.

Hinds, P.S., Vogel, R.J., \& Clarke-Steffen, L. (1997). The possibilities and pitfalls of doing a secondary analysis of a qualitative data set. Qualitative Health Research, 7(3), 408-424.

Kamil, M., \& Hiebert, E. (2005). Teaching and learning vocabulary: Perspectives and persistent issues. In: Hiebert, E.H., \& Kamil, M.L., (Eds.), Teaching and Learning Vocabulary: Bringing Research to Practice. Mahwah, NJ: Lawrence Erlbaum. p1-23.

Lemke, J. (1990). Talking Science: Language, Learning, and Values. Norwood, NJ: Ablex.

Marzano, R.J. (2004). Building Background Knowledge for Academic Achievement: Research on What Works in Schools. Alexandria, VA:

\section{ASCD.}

Marzano, R.J., Pickering, D.J., \& Pollock, J.E. (2001). Classroom Instruction that Works. Alexandria, VA: ASCD.

Meyers, G. (1991). Lexical cohesion and specialized knowledge in science and popular science texts. Discourse Processes, 14, 1-26.

Millar, R., \& Osborne, J.F. (Eds.). (1998). Beyond 2000: Science Education for the Future. London: King's College London.

Nagy, W. (2005). Why vocabulary instruction needs to be long-term and comprehensive. In: Hiebert, E.H., \& Kamil, M.L. (Eds.), Teaching and Learning Vocabulary: Bringing Research to Practice. Mahwah, NJ: Lawrence Erlbaum. p27-44.

Nagy, W.E., Herman, P., \& Anderson, R. (1985). Learning words from context. Reading Research Quarterly, 19, 304-330.

National Governors Association Center for Best Practices (NGA) and Council of Chief State School Officers (CCSSO). (2010). Common Core State Standards (English Language Arts). Washington, DC: NGAC and CCSSO.

National Institute of Child Health and Human Development (NICHD). (2000). Report of the National Reading Panel. Teaching Children to Read: An Evidence-based Assessment of the Scientific Research Literature on Reading and its Implications for Reading Instruction (NIH Publication No 00-4769). Washington DC: U.S. Government Printing Office.

National Research Council (NRC). (2013). A Framework for K-12 Science Education: Practices, Crosscutting Concepts, and Core Ideas. Washington, DC: National Academic Press.

Nyberg, A., \& Shelnut, C.M. (2004). Pre-AP: Strategies in English the Five-S strategy for Passage Analysis: College Board. Available from: http:// www.apcentral.collegeboard.com/apc/members/preap/workshop/35751. html. [Last accessed on 2019 Oct 06].

Osborne, J., \& Dillon, J. (2008). Science Education in Europe: Critical Reflections: A Report to the Nuffield Foundation. London: Nuffield Foundation.

Partnership for Assessment of Readiness for College and Careers (PARCC). (2011). Draft Model Content Frameworks for English Language Arts/ Literacy. Washington, DC: PARCC, Rotherham, AJ.

Penney, K., Norris, S.P., Phillips, L.M., \& Clark, G. (2003). The anatomy of junior high school science textbooks: An analysis of textual characteristics and a comparison to media reports of science. Canadian Journal of Science, Mathematics, and Technology Education, 3, 415-436.

Reutzel, D.R., \& Cooter, R.B.Jr. (1996). Teaching Children to Read: From Basals to Books. $2^{\text {nd }}$ ed. Englewood Cliffs, NJ: Prentice Hall.

Snow, C.E., Griffin, P., \& Burns, M.S. (2005). Knowledge to Support the Teaching of Reading: Preparing Teachers for a Changing World. San Francisco, CA: Jossey-Bass.

Stahl, S. (2005). Four problems with teaching word meanings (and what to do to make vocabulary an integral part of the instruction). In: Hiebert, E.H., \& Kamil, M.L. (Eds.), Teaching and Learning Vocabulary: Bringing Research to Practice. Mahwah, NJ: Lawrence Erlbaum. p95-114.

Szabo, V., \& Strang, V.R. (1997). Secondary analysis of qualitative data. Advances in Nursing Science, 20(2), 66-74.

Vygotsky, L.S. (1986) Thought and Language. Cambridge, MA: MIT Press

Yager, R.E. (1983). The importance of terminology in teaching K-12 science. Journal of Research in Science Teaching, 20, 577-588.

Yates, P.H., Cuthrell, K., \& Rose, M. (2011). Out of the room and into the hall: Making content word walls work. Clearing House, 84(1), 31-36.

Yore, L.D., Hand, B., \& Shelley, M.C. (2009), Gold Standard(s) of Quality Research in Science Literacy: Science Education, Reading, Statistics, and Other Adventures in Science-Based Research. Dordrecht, the Netherlands: Springer.

Yore, S.D, Bisanz, G.L., \& Hand, B.M. (2003). Examining the literacy component of science literacy: 25 years of language arts and science research. International Journal of Science Education, 25(6), 689-725. 


\section{APPENDIX A \\ Content Assessment Items}

\section{Questions}

1. A boy and a girl are sledding down a hill. The boy and the girl weigh the same, and they are using sleds that weigh the same. If the boy and girl are sledding at the same speed, which child has more kinetic energy?

a) The boy has more motion energy

b) The girl has more motion energy

c) Both of them have the same amount of motion energy

d) Neither the boy nor the girl has any motion energy

2. Object 1 and Object 2 are traveling at the same speed, but the motion energy (kinetic energy) of Object 1 is greater than the motion energy of Object 2.

Does Object 1 weigh more than, less than, or the same as Object 2?

a) Object 1 weights more than Object 2

b) Object 1 weights less than Object 2

c) Object 1 weights the same as Object 2

d) More information is needed to compare the weights of the objects

3. A girl is sitting and not moving in a chair and throws a ball. After she throws the ball, she remains still and watches the ball move through the air. While the ball is moving through the air, does the girl or the ball have more motion energy (kinetic energy), and why?

a) The girl has more motion energy because she is alive, and the ball is not

b) The girl has more motion energy because she weighs more than the ball

c) The ball has more motion energy because it is moving, and the girl is not

d) The ball has more motion energy because it is higher off the ground than the girl

4. A student places two books on a table. One book weighs less than the other book. Which book has less gravitational potential energy? (Consider the reference point to be the floor.)

a) The book that weighs less has less gravitational potential energy

b) The book that weighs more has less gravitational potential energy

c) Both books have the same amount of gravitational potential energy

d) Neither book has any gravitational potential energy

5. A girl and a boy are each holding a ball. The girl throws her ball, and the boy drops his ball. Which statement describes the motion energy (kinetic energy) of the balls while they are moving through the air?

a) Both the ball that was thrown and the ball that was dropped have motion energy

b) The ball that was thrown has motion energy, but the ball that was dropped does not

c) The ball that was dropped has motion energy, but the ball that was thrown does not

d) Neither the ball that was thrown nor the ball that was dropped has motion energy

6. Is energy transformed while a rock is falling from a cliff? Explain

a) Yes, motion energy (kinetic energy) is transformed into gravitational potential energy as the rock falls

b) Yes, gravitational potential energy is transformed into motion energy (kinetic energy) as the rock falls

c) No, because the rock lost all of its gravitational potential energy once it started to move

d) No, because one form of energy cannot be transformed into another form of energy

7. A student compresses a spring. How does the elastic energy of the spring change when the student compresses it?

a) The elastic energy of the spring increases when the student compresses it

b) The elastic energy of the spring decreases when the student compresses it

c) The elastic energy of the spring does not change when the student compresses it

d) More information is needed to tell how elastic energy changes

${ }^{1}$ Correct selection in italics 